\title{
Simetrías del terrorismo en Ardor guerrero (1995) y Plenilunio (1997), de Antonio Muñoz Molina
}

\author{
Gonzalo MARTÍN DE MARCOS \\ Pontificia Universidad Católica Madre y Maestra \\ g.martin@ce.pucmm.edu.do
}

\begin{abstract}
RESUMEN
El terrorismo etarra no ha recibido un tratamiento central en la narrativa española (salvo excepciones a comienzos del siglo XXI). Las novelas Ardor guerrero y Plenilunio, de Antonio Muñoz Molina, lo integran como elemento secundario mediante correspondencias con otros elementos principales. Así, adquiere relevancia de sentido y se convierte en objeto de reflexión moral indirecta. Mediante el análisis de la perspectiva narrativa, el espacio, los personajes y las secuencias narrativas, este artículo llama la atención sobre el hecho de que no se enjuicia el terrorismo directamente, sino que se le atribuyen juicios que sus términos de comparación sí reciben explícitamente. Por su equiparación con la violencia fascista, en el primer caso, y con la violencia común, en el segundo, estas novelas presentan una imagen crítica de ETA, que aparece como fuerza retrógrada frente a la democracia y como agente de terror. La narrativa contribuye, cuando aún no podía expresarse sin temor, al fin del terrorismo mediante sus recursos propios.
\end{abstract}

Palabras clave: Antonio Muñoz Molina, novela española, terrorismo, simetrías.

\begin{abstract}
ETA terrorism has not been given a central treatment within the Spanish narrative (with a few exceptions at the beginning of the twenty-first century). In the novels Ardor guerrero y Plenilunio by Antonio Muñoz Molina, it is integrated as a secondary element by correlation with other major elements. Thus, meaning becomes relevant and turns into a subject for indirect moral reflection. By analyzing the narrative perspective, space, characters, and narrative sequences, this article draws attention to the fact that terrorism is not directly criticized but attributed judgments that are explicitly given to its comparative terms. By equating with fascist violence, in the first case, and by common violence, in the second, these novels present a critical image of ETA which appears as a retrograde force against
\end{abstract}


democracy and as an agent of terror. The narrative contributes, even it could not be expressed fearlessly, to the end of terrorism though its own resources.

Key words: Antonio Muñoz Molina, Spanish novel, Terrorism, Symmetries.

\section{Introducción}

En Ardor guerrero y Plenilunio, de Antonio Muñoz Molina, el terrorismo se integra en las historias mediante una serie de simetrías. Son correspondencias de significado y función por medio de las cuales este elemento circunstancial cobra relevancia en el conjunto. El objetivo de este artículo es estudiar la participación de este tema en una estructura que le otorga importantes sentidos de tipo ético y social. Para ello, se analizan determinados recursos narrativos: la perspectiva ideológica y el espacio, en la primera novela; y el molde genérico, en la segunda. En Ardor guerrero (1995), se establece una dialéctica espacial entre la violencia del abertzalismo y la violencia del fascismo, según la cual el protagonista es víctima intermedia de dos nacionalismos que se resisten al establecimiento de la democracia y que marcan, asimismo, su desorientación ideológica en la Transición española. En Plenilunio (1997), el terrorismo se integra en un relato de corte policíaco cuya pautada estructura lo reduce a su condición criminal. La equiparación entre las víctimas y la equiparación entre los victimarios, en el caso de un crimen local y en el caso de ETA, permiten una reflexión sobre el terrorismo en el marco de un género que lo acoge con naturalidad.

Con este trabajo, pretende evidenciarse que la presencia del terrorismo en estas obras es circunstancial pero no accesoria, y ello supone que su participación en las ficciones, en el plano semántico, no es en absoluto irrelevante. Es cierto que ETA no ha aparecido de manera central en la narrativa española contemporánea hasta hace muy poco: Fernando Aramburu o J. Á. González Sainz, ya en el siglo XXI, han publicado, respectivamente, Los peces de la amargura (2006) y Ojos que no ven (2010); con menor resonancia crítica, Una belleza convulsa (2001), de José Manuel Fajardo, se atreve a un tratamiento resuelto del tema pero sin nombres ni siglas. Quizá por ello el tratamiento crítico de la relación entre ETA y la narrativa ha sido asimismo escaso. Destaca el estudio de Alonso Rey, que hace una relación bastante completa de los novelistas que han abordado el asunto desde el siglo XX hasta los primeros años del siglo XXI, aunque no menciona a Muñoz Molina. ${ }^{1}$ Los numerosos estudios específicos sobre este autor (que recoge Epicteto Díaz Navarro) tampoco lo tratan. En Ardor guerrero, donde su presencia es menor y sin embargo - tal como se argumentará-ineludible, Xavier Echarri, Ricardo Fernández, Luis Iglesias Feijoo o Antonio Lara no lo mencionan; sólo Lewis lo

${ }^{1}$ M. D. Alonso Rey (2007), pp. 326 y ss. 
hace. Los que han estudiado Plenilunio (Castro y Herrero, Cruz, Fernández Vázquez, Ferrari, González Castro, Grubbe, Kline, Martín Moreno, Neira, Oropesa, Ortega, Pérès, Salvador Caja, Schlickers, Sullá) se ocupan de la mayor parte de los elementos presentes en la obra pero ninguno se centra en la aparición de ETA, aunque Neira sí habla del trasfondo político de la novela ${ }^{2}$.

En la obra de Muñoz Molina, dos novelas publicadas consecutivamente en los años noventa del siglo XX emplean el mismo recurso para hablar sobre un tema que aún no se afrontaba de pleno. Así, la narrativa se convierte en marco de reflexión indirecta ${ }^{3}$ sobre asuntos de gran trascendencia moral y social. Es preciso atender a la presencia del terrorismo en obras que pueden no tratarlo de manera central, en épocas en que el terror inhibía en parte la mención expresa, a diferencia de lo que ha empezado a ocurrir a comienzos de este siglo, cuando el cese de los crímenes de ETA ha contribuido, entre otras cosas, a la libertad de expresión.

\section{Ardor guerrero (1995): la desorientación ideológica de la Transición}

En 1979, año en que transcurre la primera parte de Ardor guerrero, la sociedad española estaba aún sujeta a un sentimiento ambivalente de deseo de democracia y querencia de estabilidad. Un sentimiento que caracterizó la actitud de los españoles hacia la política durante la Transición, como señala Santos Juliá: "[t]he aspiration for freedom existed alongside the desire to mantain stability" ${ }^{\text {. }}$. Ni la oposición a Franco ni los sectores del régimen habían sabido advertir la tendencia mayoritariamente moderada del electorado español, preparado para la democracia pero temeroso de una remoción radical. El acierto del Rey había consistido en confiar a un político como Adolfo Suárez la construcción de un nuevo sistema de libertades sobre tal realidad sociológica. Sólo los crímenes de ETA y la posibilidad de una reacción retrógrada del ejército amenazaban el proceso democrático. La banda terrorista ETA, surgida en 1959, había estado explotando la represión franquista del nacionalismo vasco para su propia legitimación. Antonio Elorza indica cómo la represión reforzó la violencia:

[t]he sheer immensity of the state repression at its height (1965-75) legitimized ETA and its violent counter-response in the eyes of the very large sectors of Basque society which, through a kind of colletive complicity, provided a very real social support base. ${ }^{5}$

${ }^{2}$ H. Neira (2002), pp. 55 y ss.

${ }^{3}$ Sobre la reflexión moral indirecta, propia de la literatura, frente al tratamiento directo de la filosofía, véase M. T. López de la Vieja (2003), p. 61.

${ }^{4}$ S. Juliá (1999), p. 107.

${ }^{5}$ A. Elorza (1995), p. 333. 
Con la llegada de la democracia, y reconocidos la mayor parte de derechos del nacionalismo - exceptuada la independencia - el terrorismo debió reformular su identidad sobre la base de un supuesto colonialismo y el rechazo de aquellos a quienes no reconocía como vascos:

[o]nce the democratic Transition began (...) the radical Basque movement was forced to develop a distinct nationalist coloration of its own. Thus, from the fading memory of ETA's armed resistance to Franco, and from elements of Sabino Arana's original Nationalist creed, the Basque nationalists pieced together a radical nationalist identity. This featured a new anti-colonial version of Arana's virulent anti-Spain posture, and an insistence that the Basque language and the Basque nation were consubstantial, whichautomatically excluded the majority of the population that spoke little or no Euskara. ${ }^{6}$

Por su parte, el ejército, junto a la Falange y la Iglesia, había constituido una de las familias institucionalizadas del Régimen, como señalan Raymond Carr y Juan Pablo Fusi en su libro clásico España, de la dictatura a la democracia. Había servido de apoyo a Franco desde el levantamiento hasta más allá de su muerte:

En vida de Franco el Ejército presionó al gobierno más de una vez para que adoptara una línea más firme contra los estudiantes rebeldes y los terroristas vascos. Después de su muerte, varios generales prominentes se opusieron a lo que consideraban medidas anticonstitucionales en favor de la democracia, y se declararon dispuestos a lanzarse a otra guerra civil si era necesario para conseguir que «el franquismo continuara después de Franco, que perdurara por muchos siglos». ${ }^{7}$

En relación con este contexto, Ardor guerrero se analiza de acuerdo con dos recursos muy significativos. En primer lugar, la perspectiva narrativa, y, a continuación, el espacio como constituyente sígnico de la estructura de sentido. La perspectiva marca, como se verá, las direcciones de la desorientación ideológica. En la historia, el soldado experimenta durante el tiempo del extinto servicio militar obligatorio ("la mili") la violencia de aquellas dos fuerzas. Destinado a su pesar en el Cuartel de los Zapadores de Montaña en San Sebastián, deberá sobrevivir al mismo tiempo al fascismo de los militares que añoran el franquismo y a la violencia abertzale que rodea a la compañía. El protagonista se convierte en eje de simetría entre dos terrores, recurso ficcional mediante el cual uno y otro resultan enjuiciados por obra de su mutua correspondencia. Esto no supone una identificación de las dos

\footnotetext{
${ }^{6}$ P. W. Silver (1999), p. 62.

${ }^{7}$ R. Carr (1979), p. 37-38.
} 
violencias $^{8}$, sino una comparación en razón de su oposición a la democracia, su intolerancia y su radicalismo ideológico, y en razón-como pretende subrayarse aquí- del terror que infunden en el personaje. Si bien las prácticas fascistas de un ejército incompletamente democratizado no han de asimilarse indiscriminadamente y sin reflexión al terrorismo, al narrador le permite una dialéctica crítica entre dos nacionalismos, cuya responsabilidad en el posible fracaso de la democracia en ciernes señala en varias ocasiones:

Yo tenía la impresión de que entre unos y otros nos iban a arrastrar a todos a un desastre de banderazos y trágalas, de banderazos de ikurriña y banderazos de bandera roja y gualda, de abertzalismo y españolismo, de oír vivas roncos al ejército español y goras a ETA militarra. ${ }^{9}$

El clima pregolpista de aquellos años, conocido como "ruido de sables", envuelve toda su estancia en el País Vasco, siempre al límite de ser declarado en estado de excepción. La consolidación de la democracia, terminada la década de los setenta, se ve favorecida por la desaparición de tales tensiones: "[1] os ochenta sólo comenzaron cuando dejamos de ser rehenes de los golpistas y los terroristas" ${ }^{\prime 10}$.

Pero el equilibrio, en este juicio sobre los fanatismos, procede de la voz que narra los acontecimientos muchos años después ${ }^{11}$. En el tiempo de la historia, el soldado encarna la desorientación ideológica de una izquierda que había visto en el terrorismo una opción no totalmente repudiable de oposición al régimen fascista. Ardor guerrero es el relato de la experiencia de la mili catorce años después de acontecida, de manera que a la mirada de entonces, la de un joven aún inmaduro y desorientado, se superpone la del narrador dueño de ciertas seguridades ideológicas y morales. Así lo señala Hans-Jörg Neuschäfer:

[e]1 narrador (...) se encuentra ya en la nueva orilla donde, en el fondo, ya no tiene dudas y donde, precisamente al escribir esa memoria militar, se distancia de aquella época que durante muchos años le había perseguido aún en sus pesadillas. O sea que la memoria militar de Muñoz Molina se encuentra asentada en la certeza de las al fin alcanzadas y estabilizadas libertades democráticas. ${ }^{12}$

La legitimación que ETA halló en un régimen dictatorial la acompañó hasta los primeros compases de la democracia. La discrepancia entre estas dos visiones, la

\footnotetext{
${ }^{8}$ No quiero decir con esto que se adopte una equidistancia moral entre los terroristas y sus víctimas, pues sería incurrir en la estrategia retórica de ETA, que trata sus crímenes como un conflicto en que se enfrentan dos bandos, ambos poseedores de la misma legitimidad.

${ }^{9}$ A. Muñoz Molina (1995), p. 298.

${ }^{10}$ A. Muñoz Molina (1995), p. 231.

${ }^{11}$ Véase, para el valor ético del yo en la autobiografía, A. Loureiro (2000), p. 10.

${ }^{12}$ H. J. Neuschäfer (2007), p. 116.
} 
del recluta y la del narrador en el futuro, representa la pérdida de un crédito moral que la izquierda antifranquista le había otorgado. Debido a su amistad con Pepe Rifón, un nacionalista gallego partidario de ETA, y a la opresión del militarismo del cuartel, acometen al joven soldado sentimientos en este sentido: "Era tan fácil, y vivíamos tan agobiados por el autoritarismo militar que a mí también se me contagiaba aquella beligerancia, hasta el punto de que ya no me indignaba cuando al comprar el periódico veía en la primera página la foto de un policía o de un guardia civil asesinado" ${ }^{13}$. Muñoz Molina establece un paralelismo entre la maduración democrática de la sociedad española y la de su yo de entonces, ambos víctimas de "la incertidumbre, el titubeo y la falta de orientación"14. Es el mismo narrador quien reconoce: "No sabía nada, no estaba seguro de nada, ni de mis sentimientos ni de mis propósitos" $"$.

\section{La pugna espacial entre fascismo y abertzalismo}

Señala Luis Iglesias Feijoo que la publicación de Ardor guerrero causó perplejidad: “ ¿Se trataba de una novela, dentro del género posmoderno de la novela de no ficción? ¿Era una autobiografía de su paso por la mili? ¿O más bien unas memorias que trascendían lo personal?"'16. Es decir, que se suscitaron disquisiciones sobre el género y el asunto aledaño de la realidad y la ficción. La novela concluye con una frase con la que el novelista parece guiar la interpretación y mediante la cual estatuye explícitamente la naturaleza no ficcional del texto: "La ventaja de la ficción es que no tolera finales tan innobles" ${ }^{" 17}$. Pues bien, pese a esta declaración hay muchos elementos de ficcionalización. La propia condición autobiográfica del discurso incluye esta tendencia, como señala Ricardo Fernánde $z^{18}$. Pero, además, el tratamiento de los personajes, los saltos en el tiempo y la significación del espacio, entre otros, son procedimientos narrativos.

En particular, el espacio está semiotizado para la expresión de una dialéctica entre los dos nacionalismos. Es este el segundo recurso narrativo que, junto a la perspectiva, opera según una dinámica de simetría y cuyo análisis aporta gran parte del sentido que adquiere el terrorismo en la novela. Así, el fascismo se encarna en imágenes de opresión, encierro y aislamiento, mientras que el abertzalismo se extiende disperso en el exterior, brotando inopinadamente en la ciudad de San Sebastián y en los montes que la rodean. El primero permanece fortificado e inmóvil en un espacio hostil dominado por el segundo, ubicuo y movedizo.

\footnotetext{
${ }^{13}$ A. Muñoz Molina (1995), p. 316.

${ }^{14}$ H. J. Neuschäfer (2007), p. 111.

${ }^{15}$ A. Muñoz Molina (1995), p. 240.

${ }^{16}$ L. Iglesias Feijoo (2007), p. 167.

${ }^{17}$ A. Muñoz Molina (1995), p. 384.

${ }^{18}$ R. Fernández (2006), p. 181.
} 
El fascismo aparece por primera vez asociado al tren que conduce a miles de jóvenes a su destino militar. La renuencia de los sectores radicales del ejército al progreso democrático se expresa en estos espacios mediante su asociación con un tiempo lentificado:

El tren era como una pensión franquista, y el viaje parecía que iba a durar como una vida entera pasada en una pensión (...) Del mismo modo que el ejército era un universo arcaico, un fósil del franquismo y del africanismo de otras décadas lejanas, también los trenes en los que viajaban reclutas parecían mucho más antiguos que los trenes normales, más lentos y más viejos que ellos. ${ }^{19}$

La estancia en los espacios del fascismo exige para sobrevivir la resignación a un retroceso ideológico - "no sólo hasta los años aún recientes del franquismo, sino mucho más atrás" ${ }^{20}$ - pero también a un retroceso en el proceso de maduración que otorga al adulto la independencia de la figura paterna. Así, junto a las imágenes de la prisión proliferan imágenes del internado y el retorno de los miedos al castigo o la humillación, propios de una infancia amedrentada por la disciplina de una educación autoritaria.

La primera etapa de la mili la cumple el joven en un campamento de instrucción en las afueras de Vitoria. Se trata de un espacio vasto y desolado cuya relación con la ciudad anticipa lo que en San Sebastián se cristaliza en una dialéctica caracterizada por la violencia y el miedo. El cuartel de San Sebastián, cuya frontera con el mundo es el río Urumea, se presenta con una fisonomía contraria a la vastedad del campamento de Vitoria: "El cuartel era, en sí mismo, como una materialización o visualización de la disciplina militar, del orden absoluto y numérico al que nos sometíamos todos" ${ }^{21}$. En su interior, el tiempo se estanca creando una realidad autónoma lejos de las transformaciones democráticas de la España de principios de los ochenta, un aislamiento fomentado por la violencia abertzale que campa a su alrededor. Además, el narrador resalta a menudo su aspecto de fortaleza casi decimonónica, habitada por militares de ínfulas aristocráticas. Todo ello lo distancia de la existencia contemporánea creando una impresión de irrealidad:

[b]astaba mirar hacia el cuartel desde el otro lado del río para advertir la fantasmagoría y la insularidad de aquel edificio con aleros mudéjares y torreones de ladrillo, con piezas de ladrillo decorativas e inútiles asomando sus

\footnotetext{
${ }^{19}$ A. Muñoz Molina (1995), pp. 54-6.

${ }^{20}$ A. Muñoz Molina (1995), p. 63.

${ }^{21}$ A. Muñoz Molina (1995), p. 134.
} 
cañones entre los árboles, con una bandera que a pesar de su tamaño y de la altura del mástil en el que ondeaba también tenía algo de bandera fantasma. ${ }^{22}$

El final de la "mili" supone el abandono de este espacio y el reingreso en un mundo a cuyos derechos se había renunciado. La concesión de la llamada "cartilla blanca", documento que licencia a los reclutas, los devuelve "[a] la tierra firme y real del otro lado del río" 23 .

Por su parte, el abertzalismo y el terrorismo de ETA ostentan una ubicación difusa, marcada por signos gráficos y una movilidad táctica. El punto de vista del protagonista determina una visión externa, discontinua e impresionista, que comienza con la imagen de su destino militar desde Andalucía: el País Vasco se presenta como un espacio vitando a causa de los atentados de la banda terrorista. En su viaje hacia el norte, cobijado primero en el tren y después en el autobús que lo conducirá al campamento de instrucción, el protagonista ve las pintadas abertzales en las paredes y los frontones, signos de control del territorio. Es el primer indicio de la relación de oposición entre el exterior, reservado a ETA, y los interiores en los que se ve confinado, bajo control del militarismo. El encierro de la disciplinada vida militar produce un efecto de aislamiento e irrealidad que tales signos refuerzan: "Un letrero en euskera, un cartel con fotografías de presos etarras, la pared de un frontón furiosamente cruzada de consignas escritas con espray, me devolvían la conciencia del lugar donde estaba" 24 .

La inmovilidad de los espacios del fascismo contrasta con la mudanza del terrorismo dentro de los espacios que le son propios. Porque si por una parte éste se centra en el País Vasco y en la ciudad de San Sebastián, no hay fijeza ni permanencia, lógica estrategia de una organización ilegal que cuenta con la ventaja de la agilidad y la ligereza. En general, los intentos de las fuerzas del orden y los militares se dirigen a contener o frenar las algaradas callejeras o la penetración de los terroristas desde Francia a través de caminos rurales que vigila la policía. En otras palabras, son intentos por reducir el abertzalismo al control del estatismo. Cuando esto no es posible, los militares se aventuran al exterior desde la seguridad de sus espacios. El valor de los miliatres del cuartel en donde está destinado el protagonista se prueba en salidas al territorio callejero que apenas dominan:

Desobedeciendo consignas superiores del prudencia se paseaban por el centro de San Sebastián con el uniforme de faena (...): no sólo despreciaban a los civiles y a los oficinistas, también a los mandos que según ellos se doblegaban o se

${ }^{22}$ A. Muñoz Molina (1995), p. 195.

${ }^{23}$ A. Muñoz Molina (1995), p. 352.

${ }^{24}$ A. Muñoz Molina (1995), p. 116. 
dejaban corromper y humillar por los políticos y salían siempre de paisano o cruzaban las avenidas de la ciudad precedidos y seguidos por jeeps de escolta. ${ }^{25}$

Pero los elementos más extremistas del ejército practican incursiones al exterior fuera de la ley. Entre 1975 y 1980 el Batallón Vasco Español (BVE), organización terrorista paramilitar, llevó a cabo atentados contra los militantes de ETA y su entorno. En la novela, los militares más radicales del cuartel, oficiales filofascistas, emplean técnicas semejantes a los abertzales para boicotear sus actos de celebración:

$[\mathrm{u}] \mathrm{n}$ certamen de bertsolaris o un baile eran interrumpidos por otros individuos también encapuchados o con las caras tapadas por medias, que disparaban pistolas al aire o derribaban a tiros las botellas de una casa abertzale, se abrían paso entre el público golpeando furiosamente y al azar con porras de goma iguales que las de la policía, incendiaban una ikurriña y se marchaban luego en coches sin matrícula dando vivas a España. ${ }^{26}$

El BVE cometió decenas de atentados. Sus acciones, igual que las de grupos herederos como los GAL, se muestran en la novela como correrías desde los espacios del interior a los espacios de la movilidad exterior, en terreno abertzale. Como tales, corren riesgo de fracasar, tal como le ocurre al sargento Martelo, uno de los oficiales más temidos del cuartel, a quien ponen en fuga y le arrebatan la pistola.

Así, el terrorismo de estado en la novela adopta la movilidad como estrategia de control del terreno hostil, imposible de reducir a la inmovilidad por medios legales y democráticos. De hecho, la calle, donde se libran batallas que el protagonista comienza a observar con indiferencia, es escenario de la espiral de violencia que se articula según un esquema de acción-represión-reacción, que había legitimado a ETA durante la dictadura ${ }^{27}$, pero que ahora se presenta como un resabio del período franquista en los albores de la democracia:

Al general gobernador militar le habían disparado a quemarropa en la cabeza (...) En Rentería, unos meses antes, varias compañías de antidisturbios habían entrado a saco arrasándolo todo, disparando a ciegas contra los escaparates de las tiendas y las ventanas de las casas en un paroxismo de barbarie, en una exasperación homicida de miedo que a su vez alimentaba la embriaguez homicida de los terroristas. $^{28}$

\footnotetext{
${ }^{25}$ A. Muñoz Molina (1995), p. 172.

${ }^{26}$ A. Muñoz Molina (1995), p. 298.

${ }^{27}$ A. Elorza (1995), 333.

${ }^{28}$ A. Muñoz Molina (1995), 200.
} 
La consecuencia de esta dicotomía entre la seguridad del interior (muy relativa, pues el recluta vive sometido al furor fascista de muchos oficiales) y la violencia etarra del exterior es un retrato gris de la ciudad de San Sebastián. Tom Lewis, previa justificación de la crítica literaria política y bajo presupuestos marxistas, reprocha a Antonio Muñoz Molina haber tergiversado la imagen de una ciudad que tradicionalmente había gozado de una fama de armonía entre clases sociales, y también por haber contribuido así (no sólo con sus novelas, sino con sus críticas en la prensa a los votantes de los partidos proetarras tras el secuestro de Miguel Ángel Blanco) al clima social que propició la ilegalización de Herri Batasuna el 16 de enero de 2004, medida concebida por Lewis como un acto de represión ${ }^{29}$. Pero la imagen de San Sebastián, independientemente del juicio político que a Lewis le merezca el autor ${ }^{30}$, está determinada en el texto por la subjetividad del recluta que, si bien padece los rigores del cuartel, ve en el exterior una amenaza que a sí mismo lo considerará un objetivo. En general, el cuartel, espacio cerrado del fascismo, se opone a la ciudad como una plaza en territorio enemigo. Esta dialéctica, que explica también el período en el campamento de Vitoria y su relación con la ciudad, se agudiza en San Sebastián como parte del recurso de la simetría en el que se integra el terrorismo de ETA:

Los sábados y domingos por la mañana matrimonios perfectamente respetables asistían del brazo en el Bulevar a las manifestaciones encabezadas por grandes fotografías de presos y banderas vascas con crespones negros y con la serpiente y el hacha de la insignia etarra. Mientras tanto, al otro lado del Urumea, por encima de los árboles y de los aleros del cuartel, una descomunal bandera española con el escudo franquista ondeaba al viento que venía río arriba del mar. $^{31}$

\section{Plenilunio (1997): el terrorismo en el relato criminal}

A diferencia de la obra anterior, Plenilunio no suscitó perplejidades. Su adscripción genérica, si bien no estricta, tenía la novela criminal como claro referente. Sin embargo, la intervención del terrorismo como elemento circunstancial a la trama central complica el sentido de un género tan pautado. La novela cuenta la investigación y final detención del violador y asesino de una niña. Los hechos ocurren en una ciudad innominada del sur de España a la que acude un comisario destinado anteriormente en el País Vasco, en donde ha sufrido, junto a su mujer, el acoso de ETA. Lejos de hallarse a salvo de la banda, el comisario acaba cayendo herido bajo los disparos de un terrorista que lo ha seguido hasta allí y lo ha vigilado

\footnotetext{
${ }^{29}$ T. Lewis (2005), p. 334.

${ }^{30}$ En efecto, Lewis extiende su juicio político de la figura del autor a la obra, y conecta ambas en un todo legitimado por la crítica política.

${ }^{31}$ A. Muñoz Molina (1995), p. 201.
} 
mientras él buscaba al asesino de la niña. Aunque parece sobrevivir al atentado, se convierte en víctima del etarra tal como Fátima, la niña asesinada, lo fue del violador. En este apartado se estudian las simetrías que la novela establece gracias a su asunción del molde genérico de la novela criminal: en primer lugar, en los procesos de búsqueda; y en segundo lugar, en los criminales y en las víctimas. Estas correspondencias crean, para el terrorismo de ETA, un sentido crítico forjado sobre una trama criminal que no lo tiene como asunto central. Es por tanto el género, con dos de sus ingredientes constituyentes, el marco determinante del significado del terrorismo de ETA.

En el conjunto de la narrativa de Muñoz Molina esta novela no gozó, poco después de su publicación, del aprecio de la crítica. Sabine Schlickers lamentaba en 2000 la poca atención académica que había despertado ${ }^{32}$, y criticaba la repugnancia que a Jordi Gracia le merecía el tratamiento de la maldad en la novela ${ }^{33}$. Santos Alonso, en su repaso de la narrativa española de la década de 1990, la ubica dentro de la tendencia realista y objetivista. Sin embargo: "Lo que siempre había caracterizado a Muñoz Molina, es decir, la suspensión, el misterio, la potencia verbal y la creación de caracteres, se soluciona aquí con maneras demasiado planas" ${ }^{\prime 4}$. En general, parece que no fue bien acogido el empleo de una factura más clásica para la expresión de unas certidumbres morales y ontológicas alejadas de las tendencias posmodernistas que sí habían aparecido en obras anteriores de este autor. La neta distinción entre el bien y el mal o la claridad de los tipos-el comisario, el asesino, la víctima, la amante-están al servicio del retrato comprometido con las víctimas del horror y cuyo paralelo con las víctimas del terrorismo señalan tanto Schlickers ${ }^{35}$ como José Manuel Begines Hormigo ${ }^{36}$. Para este último, uno de los temas de la novela, la apariencia engañosa tras la que se oculta el mal, está anticipado en "Nadie lo diría", artículo publicado en El País en 1990 a propósito de la detención del etarra de origen francés Henri Parot, "Unai". Es decir, que si bien la novela no contiene las audacias expresivas y la profundidad artística de obras como El jinete polaco, presenta una estructura que permite la integración diáfana del terrorismo en un todo del que obtiene un sentido ético.

Para José Valles Calatrava, las consideraciones pragmáticas y socioculturales que abren el género criminal a textos muy diversos no impiden determinar tres componentes básicos: un hecho delictivo como tema central, la acumulación de funciones narrativas referidas a ese hecho o a su investigación, y el enfrentamiento antagónico entre crimen y justicia, encarnados en el criminal y el investigador ${ }^{37}$.

\footnotetext{
${ }^{32}$ S. Schlickers (2000), p. 280.

${ }^{33}$ J. Gracia (1997), p. 119.

${ }^{34}$ S. Alonso (2010), p. 215.

${ }^{35}$ S. Schlickers (2000), p. 283.

${ }^{36}$ J. M. Begines Hormigo (2006), p. 312

${ }^{37}$ J. Valles Calatrava (1991), p. 31.
} 
Pues bien, de acuerdo con ello es posible catalogar Plenilunio como novela criminal, un marchamo más comprensivo que el de novela policíaca, y que ya incluye la secuencia elemental de la que participa el terrorismo: "Crimen - Búsqueda / No Búsqueda - Localización / No localización" 38 . Así, la violación y asesinato de Fátima desencadenan la búsqueda del culpable a cargo del comisario, trasladado a la ciudad desde el norte. En pleno proceso de búsqueda la secuencia se reinicia, porque el asesino comete otra violación - esta vez fracasa en su intento de asesinato-que precipita la localización final. En este proceso, el antagonismo de uno y otro se certifica por el hecho de que ambos persiguen objetivos enfrentados: el uno huye de quien quiere atraparlo.

Sin embargo, imbricada con esta, hay otra secuencia, sólo a ratos visible en el discurso narrativo, pero finalmente revelada, que invierte los términos de tal dinámica. En su actuación criminal más básica, los terroristas son objetivo de la investigación policial que puede o no acabar con su detención, pero en Plenilunio se reproduce una inversión según la cual el investigador se torna víctima del terrorista y su objetivo no será detenerlo sino librarse de su acoso y de sus intentos de asesinarlo. Estas dos secuencias, la de la búsqueda del violador por el policía y la del acoso al policía por ETA, se cruzan en el comisario, que se convierte en la conexión que permite establecer la primera correspondencia ${ }^{39}$, la que se refiere a los procesos de búsqueda en el género criminal.

Desde el principio abundan las referencias al pasado del comisario en el País Vasco. Unas aluden directamente a su estancia allí y la difícil experiencia del ostracismo social, y otras a los hábitos de contravigilancia que todo amenazado por ETA interioriza y lleva consigo tiempo después. Antes de que se confirme la doble condición del comisario como investigador-vigilado, tales referencias son indicio de la secuencia criminal que se mantendrá en un segundo plano:

Salía de la oficina, les decía adiós con un gesto a los guardias de la puerta, miraba a un lado y a otro de la calle, con el miedo antiguo, todavía intacto, con el recelo de mirar a quienes se acercaban y de fijarse si había algún coche aparcado en una posición sospechosa, y nada más acercarse hacia el centro de la plaza donde estaba la estatua del general se convertía en un desconocido y comenzaba su búsqueda. ${ }^{40}$

\footnotetext{
${ }^{38}$ J. Valles Calatrava (1991), p. 67.

${ }^{39}$ En realidad, el entrecruzarse de estas dos secuencias reproduce en la literatura la realidad social por la cual quienes persiguen a los terroristas huyen, al mismo tiempo, de ellos. La estructura de la novela criminal permite reflejar estas inversiones y aportar para ellas un significado literario.
}

${ }^{40}$ A. Muñoz Molina (1997), p. 16. 
De manera que el comisario toma las medidas habituales para prevenir un atentado, pero sin saber a ciencia cierta si lo están acechando: sentarse en los restaurantes de cara a la entrada, examinar los bajos del coche cada mañana, registrar los vehículos sospechosos, explorar las calles por donde transita, evitar que las cámaras que cubren morbosamente la investigación del asesinato de Fátima graben su rostro y desvelen su paradero. Mediado el libro averiguamos que, en efecto, existe una vigilancia. Un terrorista le sigue y toma nota minuciosa de sus pasos en un informe que remitirá a sus superiores: "«Se levanta todas las mañanas a las ocho. Lo primero que hace es asomarse en pijama a la calle. Aparta un segundo las cortinas y mira primero las ventanas de enfrente y luego a la calle. Se fija en los coches aparcados para comprobar las matrículas. Sale hacia las ocho y media...»"41. Es decir, mientras los terroristas lo vigilan y siguen con el propósito de asesinarlo, él busca al violador de Fátima, que se le oculta tal como él pretende ocultarse de aquellos. Francisco González Castro señala que en Plenilunio la

[d]ialéctica entre visibilidad y ocultamiento condiciona la representación de los personajes, sobre todo la del criminal (...) Si de acuerdo con la convención del género policíaco, al inspector lo anima el deseo de saber y de averiguar, al asesino se destaca su condición evasiva, por su necesidad de escapar a la labor analítica e interpretativa del detective. ${ }^{42}$

Con esta dialéctica de la convención policíaca se cruza, como he señalado, la otra, por la cual el detective ostenta a su vez una condición evasiva y los terroristas hacen lo posible por acercársele. La diferencia estriba en que la intención de la ley es pública y legítima - conocida por el violador en los medios de comunicación y ejecutada por un individuo investido legalmente para ello-, mientras que la de los terroristas ha de permanecer oculta porque la visibilidad es prerrogativa del estado. El comisario desconoce que lo siguen, pero toma medidas impulsado por la costumbre del miedo, adquirida en el País Vasco, y se confirma a sí mismo como perseguido.

De esta primera simetría se desprende la segunda, la que establece correspondencias entre los victimarios y entre las víctimas, tipos característicos del género criminal: a los terroristas se los asocia con el violador y al comisario con la niña asesinada. Schlickers y Bengines Hormigo ya mencionan tales correspondencias, más deducidas del compromiso público del escritor contra ETA que sobre la base del texto. Pero en la novela, sin necesidad de acudir al papel social de un escritor comprometido, hay algunos indicios de la primera equiparación que pueden hallarse en boca del comisario o del mismo violador. Tras haber cometido el criminal su segunda violación e ignorante aún de que su víctima

${ }^{41}$ A. Muñoz Molina (1997), p. 163.

${ }^{42}$ F. González Castro (2004), p. 274. 
logró sobrevivir, el comisario se refiere así a la estrategia policial de ocultar a la prensa el hecho: "Quiero que espere y que no ocurra nada (...) Que oiga la radio todos los días, a todas horas, que se ponga nervioso esperando el telediario. A estos les pasa como a los terroristas. En el fondo les colma la vanidad ver sus hazañas en la prensa" ${ }^{43}$. Y más adelante, una vez capturado, establece otro paralelismo:

«Pero las víctimas no le importan a nadie», pensaba: merecía mucha más atención su verdugo (...) Al menos no le rinden homenajes públicos, como hacen en el norte (...), al menos no pondrán su nombre a una calle, no sacarán su retrato de una iglesia y lo pasearán en alto como si fuera un estandarte religioso. ${ }^{44}$

El mismo violador, cuando pasea frente a la comisaría, desafiante y excitado por el riesgo, fantasea: "Ahora imagina que es un terrorista, que saca una pistola del bolsillo de la cazadora y se la pone al guardia delante de la cara y le revienta el cerebro contra la pared. Si él quiere, si le da la gana, si le sale de la punta de la polla, cualquier cosa que se le ocurra puede hacerla" ${ }^{45}$. Es decir, para el comisario el terrorismo es el tipo de criminalidad en cuya lucha está entrenado, de ahí que decida aplicar una de sus estrategias para hallar al violador: despertar su vanidad insatisfecha al no ver su segundo crimen publicitado. En cambio, para el violador el terrorista es modelo de arrogancia y triunfo sobre la autoridad que los persigue. En ambos casos, el terrorismo constituye una referencia mayor para un crimen común, local y desideologizado.

La segunda equivalencia corresponde a las víctimas. En términos funcionales, y de acuerdo con el esquema de persecución que Valles Calatrava propone para el relato criminal, al comisario le corresponde la misma posición que a Fátima o Paula. Pero, además, su condición de víctima queda confirmada por el miedo que a él y a su mujer los persigue desde su estancia en el País Vasco. La asociación entre el miedo y el terrorismo es básica, desde la acuñación del término en la época de $L e$ Terreur $^{46}$. Casi todas las definiciones sobre el terrorismo incluyen esa noción: "[t]oda actividad criminal organizada, que produce actos de violencia física con miras a intimidar a un sector de la población, con la finalidad de obtener ventajas políticas, económicas, religiosas y/o nacionalistas" ${ }^{\prime 7}$. En la novela, el miedo es una constante. La intimidación que sufrieron en el País Vasco los acompaña, al comisario y a su mujer, en su traslado al sur, como un hábito asimilado y que pasa a formar parte del carácter:

\footnotetext{
43 A. Muñoz Molina (1997), p. 355.

${ }^{44}$ A. Muñoz Molina (1997), p. 455.

${ }^{45}$ A. Muñoz Molina (1997), p. 212.

${ }^{46}$ J. Caro Baroja (1989), p. 19.

${ }^{47}$ F. Alonso Fernández (2002), p. 31.
} 
A lo que más le costaba acostumbrarse al inspector era a la ausencia del miedo. Había vivido y respirado miedo durante demasiado tiempo, se lo había administrado a sí mismo como una vacuna, una dosis de veneno necesaria para lograr una cierta inmunidad, y ahora, cuando ya no lo necesitaba, el miedo seguía con él, siempre una costumbre demasiado antigua para librarse de ella en días o semanas, en los pocos meses que llevaba lejos de Bilbao. ${ }^{48}$

Es más, en el caso de su mujer el miedo ha llegado a perturbarla. Las amenazas recibidas por medio de llamadas anónimas la aterraban en el apartamento de Bilbao mientras él sufría el miedo de no regresar vivo por la noche. En el sur, su estado es tal que permanece ingresada en un sanatorio mental todo el tiempo que el inspector dedica a investigar ${ }^{49}$. El miedo hermana al inspector con las víctimas del violador y aviva su empatía hacia ellas: "Fátima había tenido varias horas de lento suplicio para comprender lo que iba a sucederle, pero quizás el pavor la había hipnotizado hasta cegarle la conciencia" ${ }^{50}$. Uno y otras acaban sufriendo la acechanza, la violencia y el terror.

La equiparación de las víctimas, criminales y procesos de búsqueda entre las dos líneas de la historia - los crímenes contra las niñas y el acecho del terrorismodespoja a ETA de cualquier ropaje ideológico y la expone en su desnuda perpetración del terror. El terrorismo se incorpora a una trama cuyo primer plano está reservado para el horror de un crimen común y que funciona como reflejo deslegitimador. Al iluminar, por asimilación con la violación y el asesinato, lo que tiene de mera violencia y muerte, el texto centra la atención sobre derechos universales, como la vida y la dignidad personal ${ }^{51}$. El pensamiento, fuera de los confines de la filosofía, se inscribe en estructuras narrativas y géneros que funcionan como moldes para la reflexión moral. El relato criminal al que se adscribe Plenilunio permite equiparaciones mediante las cuales resulta manifiesta la reprobación del terrorismo.

\footnotetext{
48 A. Muñoz Molina (1997), p. 100.

${ }^{49}$ El miedo en la novela es una emoción que hermana al inspector con las víctimas, pero únicamente cuando se da en un grado controlable. En cambio, en el caso de la mujer, el miedo superó la barrera psíquica que la separaba de la demencia. En este estado, el miedo se convierte en un factor de distancia más que de proximidad. De este modo el terrorismo contribuye al distanciamiento del inspector y su mujer.

${ }^{50}$ A. Muñoz Molina (1997), p. 101.

${ }^{51}$ Es precisamente la afirmación implícita de unos valores universales lo que aleja a esta novela del estereotipo moral que se le atribuye a la literatura posmodernista, una de las razones por las cuales pudo haber cosechado tanta incomprensión crítica.
} 


\section{Conclusión}

Ardor guerrero y Plenilunio se publicaron aún en la década de los noventa, en un tiempo en que la literatura se comprometía de costado contra el terrorismo de ETA. Aún no había novelas que lo tuvieran como asunto central y, cuando aparecía, este es el caso, lo hacía de forma marginal. No obstante, por su correspondencia con otros elementos del relato, ya sea el espacio, ya sean los personajes, y estas correspondencias reforzadas por el molde genérico en el que se integra - una autobiografía novelada o una novela criminal clásica—, la relevancia del terrorismo se potencia más allá del papel secundario que exhibe en la trama. En otras palabras, el escritor logra otorgarle un sentido moral por obra de unos recursos narrativos que permiten eludir un tratamiento directo. Desde su posición en el campo social, la literatura ha contribuido a la superación del terror con sus herramientas propias. A diferencia de la ética o el ensayo, la novela abriga la posibilidad de una reflexión indirecta sobre la realidad y sus desafíos. Con estas dos novelas, Muñoz Molina ha podido concurrir al fin del terrorismo. Por medio del siempre vidrioso equilibrio entre artificio y compromiso, logra una feliz asociación entre literatura y ética.

\section{Obras citadas}

ALONSO REY, María Dolores: "La imagen del terrorista en la novela española actual", Lectura y signo: revista de Literatura 2.1 (2007), pp. 325-54.

ALONSO, Santos: La novela española en el fin de siglo: 1975-2001, Madrid, Mare Nostrum, 2010.

ALONSO-FERNÁNDEZ, Francisco: Fanáticos terroristas. Claves psicológicas y sociales del terrorismo, Barcelona, Salvat, 2002.

BEGINES HORMIGO, José Manuel: Personajes y estilo en la narrativa de Antonio Muñoz Molina, Sevilla, Padilla, 2006.

CARO BAROJA, Julio: Terror y terrorismo. Esplugues de Llobregat (Barcelona): Plaza y Janés [etc.], 1989. Impreso.

CARR, Raymond y Juan Pablo Fusi: España, de la dictadura a la democracia, Barcelona, Planeta, 1979.

ECHARRI, Xavier: "Interrupciones en Ardor Guerrero de Antonio Muñoz Molina: Globalización, posmodernidad y militarismo", Colorado Review of Hispanic Studies, 1,1 (2003), pp. 65-77.

ELORZA, Antonio: «Some Perspectives on the Nation State and Autonomies in Spain», Spanish Cultural Studies: An Introduction: The Struggle for Modernity, Helen Graham and Jo Labanyi (eds.), Oxford [England], New York, Oxford University Press, 1995, pp. 332-5.

FERNÁNDEZ, Ricardo: «Exilio, memoria y líneas de sombra. A propósito de Ardor guerrero, de Antonio Muñoz Molina», Siglo XXI. Literatura y cultura españolas, 4 (2006), pp. 173-82.

GONZÁlEZ CASTRO, Francisco: «Los perfiles del asesino en Plenilunio de Antonio Muñoz Molina», en Actas del IV Congreso de la Asociación 
Internacional de Hispanistas: Nueva York, 16-21 de julio de 2001, Newark (Delaware), Juan de la Cuesta, [2004], pp. 273-79.

GRACIA, Jordi: «El precio del espanto», Cuadernos hispanoamericanos, 564 (1997), pp. 119-21.

IGLESIAS FEIJOO, Luis: «'Memoria amarga de mí'»: individuo y sociedad en Ardor guerrero, de Antonio Miuñoz Molina», Hispanística XX, 25 (2007), pp. 167-80.

JULIÁ, Santos: «History, politics, and culture, 1975-1996», The Cambridge Companion to Modern Spanish Culture, David T. Gies (ed.), Cambridge, Cambridge University Press, 1999, pp. 104-22.

KLINE, Carmenza: "Plenilunio y los cuestionamientos existenciales de Antonio Muñoz Molina", Cuadernos de Literatura, 5, 9 (1999), pp. 61-9.

LARA, Antonio: “Ardor guerrero", en Ética y estética de Antonio Muñoz Molina, I. Andres-Suárez (ed.), Cuadernos de Narrativa 2, pp. 161-175.

LEWIS, Tom: «España 'fuera de sí': Representing San Sebastián in Antonio Muñoz Molina's El invierno en Lisboa y Ardor guerrero», Spain Beyond Spain: Modernity Literary History, and National Identity, Brad Epps and Luis Fernández Cifuentes (eds.), Associated University Press, Cranbury, NJ, 2005, pp. 331-59.

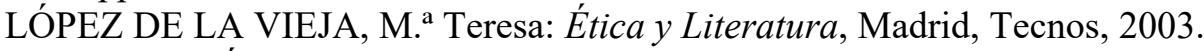

LOUREIRO, Ángel: The Ethics of Autobiography, Nashville, Vanderbilt University Press, 2000.

MARTÍN MORENO, Ana Isabel (2003), "La violencia como eje central en Plenilunio, de Antonio Muñoz Molina", en Violencia y género, M. Dolores Adam Muñoz y M. José Porro Herrera (eds.), Córdoba, Universidad de Córdoba, pp. 223-238.

MUÑOZ MOLINA, Antonio: Ardor guerrero, Madrid, Alfaguara, 1995.

---: «Nadie lo diría», El País, 15 de abril de 1990.

---: Plenilunio, Madrid, Alfaguara, 1997.

NEIRA, Hernán (2002), "Plenilunio de Antonio Muñoz Molina: Trasfondo políticoliterario de un crimen sexual", Taller de Letras, 31, pp. 55-74.

NEUSCHÄFER, Hans-Jörg: «1979: La Transición española como crisis de orientación (en la perspectiva de Rosa Montero y de Antonio Muñoz Molina)», Memoria literaria de la transición española, Javier Gómez Montero (ed.), Madrid. Iberoamericana ; Frankfurt am Main: Vervuert, 2007, pp. 110-18.

OROPESA, Salvador A. (1998), "Caos, desencanto, esperanza y construcción: Plenilunio (1997) de Antonio Muñoz Molina", RLA: Romance Languages Annual, 10.2, pp. 756- 62.

PÉRÈS, Christine: "Ardor guerrero d"Antonio Muñoz Molina: mémoire militaire de J-54", en Le Moi et l "espace. Autobiographie et autofiction dans les 
littératures d"Espagne et d"Amérique latine, Actes du colloque international des 26, 27 et 28 septembre 2002, dir. Jacques Soubeyroux, Saint-Etienne, Publications de $1^{\text {ec }}$ Université de Saint-Etienne, pp. 221-235.

---: "Chronique de deux morts annoncées: El hijo (Horacio Quiroga) et Plenilunio (Antonio Muñoz Molina)", en La voix narrative, actes du colloque organisé par le Centre de Narratologie Appliquée à Nice en avril 2000, ed. Jean-Louis Brau, Vol. 2, Nice, Publication de la Faculté des Lettres, Arts et Sciences Humaines, pp. 351-360.

ORTEGA, José: "Una reflexión sobre la maldad: Plenilunio de Muñoz Molina", Iris, 24 (1999), pp. 157-164.

SALVADOR CAJA, Gregorio: "Genio literario y certidumbre moral: sobre Plenilunio de Antonio Muñoz Molina”, Saber leer, 116 (1998), pp. 4-5.

SCHLICKERS, Sabine: «Los espejismos de la historia y los abismos del deseo: Beatus Ille (1986), Plenilunio (1997) y Carlota Fainberg (1999) de Antonio Muñoz Molina», Cuadernos de Investigación Filológica, XXVI (2000), pp. 237-90.

SILVER, Philp W: "The Basque Country". The Cambridge Companion to Modern Spanish Culture, David T. Gies (ed.), Cambridge, U.K.; New York: Cambridge University Press, 1999, pp54-67.

SULLÁ, Enric: "Aspectos de la adaptación cinematográfica: a propósito de Plenilunio, novela y película", Lecturas e imágenes, 2 (2003), pp. 217-229.

VALLES CALATRAVA, José: La novela criminal española, Granada, Universidad de Granada, 1991. 